\section{A comprehensive approach needed to address regional variation}

The study by Tu and colleagues ${ }^{1}$ in CMAJ highlights that populations in some Local Health Integration Networks (LHINs), most notably in northern Ontario, had almost twice the incidence of cardiovascular disease compared with those in southern Ontario, with geographic variation correlated with differences in access to preventive ambulatory health care services. The authors and accompanying commentary proposed more equitable access to such care as a solution to improving cardiovascular outcomes.

Although a contributing factor, if the ultimate aims are to improve health, health equity and sustainability of the health system, focusing primarily on improvements in access to care misses the mark. We would argue that a comprehensive approach is required, incorporating healthy public policies to support health and to level-up socioeconomic disadvantage. With a $\$ 4.9$ billion reduction in health care costs over 10 years, Ontario showed the power of such policies (primarily through measures of tobacco control). ${ }^{2}$ Furthermore, international research has confirmed the need to target socioeconomic circumstances in addition to traditional risk factors to reduce premature death. $^{3}$

Examples of healthy public policies supported by the Canadian Medical Association include substantial increases in tobacco taxation, ${ }^{4}$ designing communities to be walking and cycling friendly, 5,6 and improving the social and economic circumstances of Canadians ${ }^{7}$ (including via a guaranteed annual income ${ }^{8}$ and improved food security ${ }^{9}$.

This study was not designed to assess the effectiveness of comprehensive approaches or healthy public policy. However, the conversation about health must always include more than access to health care, if all Canadians are to have full and equal opportunities for health. ${ }^{10,11}$

\section{Charles Gardner MD MHSc}

Medical Officer of Health, Simcoe

Muskoka District Health Unit, Barrie, Ont.

\section{Lisa Simon MD MPH}

Associate Medical Officer of Health, Simcoe Muskoka District Health Unit, Barrie, Ont.

\section{Penny Sutcliffe MD MHSc}

Medical Officer of Health, Sudbury \&

District Health Unit, Sudbury, Ont.

Lawrence C. Loh MD MPH

Acting Medical Officer of Health, Peel

Public Health, Mississauga, Ont.

Lynn Noseworthy MD MHSc

Medical Officer of Health, Haliburton, Kawartha, Pine Ridge District Health Unit, Port Hope, Ont.

\section{Rosana (Pellizzari) Salvaterra MD MSc}

Medical Officer of Health, Peterborough

Public Health, Peterborough, Ont.

\section{Kit Young-Hoon MBBS MPH MSc}

Medical Officer of Health, Northwestern

Health Unit, Kenora, Ont.

- Cite as: CMAJ 2017 June 19;189:E840. doi: $10.1503 /$ cmaj. 733075

\section{References}

1. Tu JV, Chu A, Maclagan L, et al.; Cardiovascular Health in Ambulatory Care Research Team (CAN-
HEART). Regional variations in ambulatory care and incidence of cardiovascular events. CMAJ 2017;189:E494-501.

2. Manuel DG, Perez R, Bennett C, et al. $A \$ 4.9$ billion decrease in health care expenditure: the ten-year impact of improving smoking, alcohol, diet and physical activity in Ontario. Toronto: Institute for Clinical Evaluative Sciences; 2016.

3. Stringhini S, Carmeli C, Jokela M, et al.; LIFEPATH consortium. Socioeconomic status and the $25 x$ 25 risk factors as determinants of premature mortality: a multicohort study and meta-analysis of 1.7 million men and women. Lancet 2017;389: 1229-37.

4. Tobacco control (update 2008) [policy]. Ottawa: Canadian Medical Association; 2008. Available: www.cma.ca/Assets/assets-library/document/en/ advocacy/policy-research/CMA_Policy_Tobacco_ Control_Update_2008_PD08-08-e.pdf (accessed 2017 Apr. 8).

5. Active transportation [policy]. Ottawa: Canadian Medical Association; 2009. Available: http://policybase.cma.ca/dbtw-wpd\%5CPolicy pdf\%5CPD09-04.pdf (accessed 2017 Apr. 8).

6. The Canadian Medical Association Policy on the Built Environment and Health [policy]. Canadian Medical Association; 2013. Available: http://policybase.cma.ca/dbtw-wpd\%5CPolicy pdf\%5CPD14-05.pdf (accessed 2017 Apr. 9).

7. Health equity and the social determinants of health: a role for the medical profession [policy]. Ottawa: Canadian Medical Association; 2013. Available: www.cma.ca/Assets/assets-library/ document/en/advocacy/PD13-03-e.pdf (accessed 2017 Apr. 7).

8. Canadian Medical Association. Resolutions adopted (confirmed). 148th Annual Meeting of the Canadian Medical Association; 2015 Aug. 24-26; Halifax.

9. Canadian Medical Association. Resolutions adopted (unconfirmed). 147th Annual Meeting of the Canadian Medical Association; 2014 Aug. 18-19; Ottawa [delegates' motions].

10. World Health Organization, Health and Welfare Canada, The Canadian Public Health Association. Ottawa Charter for Health Promotion: an internaltional conference on health promotion. Proceedings of the First International Conference on Health Promotion; 1986 Nov. 17-21; Ottawa. Ottawa: Canadian Public Health Association; 1986:1-5.

11. Health equity resources. Sudbury (ON): Sudbury \& District Health Unit; 2016.

Competing interests: None declared. 